as the mass of air situated above $106 \mathrm{~km}$. at floodtide.

When adopting all the assumptions and results given in "The Propagation of Radio Waves" by P. O. Pedersen (Copenhagen, 1927), it is possible to show how the conductivity of the upper atmosphere $(130-160 \mathrm{~km}$.$) is influenced by the different states$ during ebb-tide and flood-tide. Let us assume that the mass of air above a certain height varies with height in accordance with an exponential function, and let us consider, within the conducting layer, a thin layer under normal conditions and with a certain conductivity. Then the problem consists in finding the variation of the conductivity caused by the atmospheric tide. On account of the slower decrease in the vertical direction of the mass of air above a certain height, a thin layer with the same electric properties as the above-mentioned thin layer will grow thicker at flood-tide; while at ebb-tide a corresponding thin layer will grow thinner. The total conductivity will therefore vary according to the atmospheric tide. For the place of observation $\left(70^{\circ}\right.$ northern latitude), the total conductivity is found to be $4 \cdot 3$ per cent greater at flood-tide than at ebb-tide.

Considering the lunar diurnal magnetic variation as a variation caused in the solar diurnal variation by tidal forces, and supposing proportionality between the conductivity in the upper atmosphere and the magnitude of magnetic variations (S. Chapman), it is found from the variations of the magnetic declination that near the equator (Batavia) the conductivity at flood-tide is 21 per cent higher than at ebb-tide. For latitude $70^{\circ}$ an increase of 2.5 per cent in the conductivity from ebb-tide to flood-tide is to be expected. The discrepancy with the above result is removed when, instead of a supposed temperature of the stratosphere of $-54^{\circ} \mathrm{C}$, a temperature of $-78^{\circ} \mathrm{C}$. is used; after Dobson (Proc. Roy. Soc., A, vol. 103, pp. 339-342) such a temperature of the stratosphere may be possible during the nights in which the measurements of the base-heights of the aurora have taken place. A consequence of the above is that the height of the conducting layer will vary during the lunar day. In latitude $45^{\circ}$ a variation of 25 per cent from the mean height may be expected, a point on which the investigation by radio waves may be able to throw some light.

Summarising, it may be said that the heights of the base of the aurora are able to give information on the tide of the upper atmosphere and thereby on the variation of the electric conductivity in the regions considered; further, that certain observed magnetic variations seem to confirm the result found. The existence of a resulting enormous variation of the height of the conducting layer may be tested by - means of radio waves.

Meteorologisk Institut,

J. Egedal.

Kjøbenhavn, Mar. 25.

No. 3104, VoL. 123]

\section{A Violation of the Selection Principle for the Principal Quantum Number.}

ONE of the selection principles, for the case of X-ray spectra, states that the principal quantum number must change in any electron transition. A thorough investigation was carried out by Coster (Phil. Mag., 43, p. $1070 ; 1922$ ) to determine if lines could be found corresponding to electron transitions between $L$ levels, but no such lines were observed. No violations of the principal quantum number selection rule have yet been found. By using the grating method, Thibaud and Soltan (Journal de Physique, 8, p. 485 ; 1927. Phys. Zeit., 29, p. 241 ; 1928 ) found two new lines for the elements tantalum (73), tungsten (74), platinum (78), and gold (79), and they also found that the values of $\nu / R$ for these lines corresponded approximately to those given by Bohr

LINE WITH SHORTER WAVE-LENGTH.

\begin{tabular}{|c|c|c|c|c|c|c|}
\hline \multirow{3}{*}{$\begin{array}{l}\text { Thibaud } \\
\text { and } \\
\text { Soltan. }\end{array}$} & \multicolumn{6}{|c|}{ 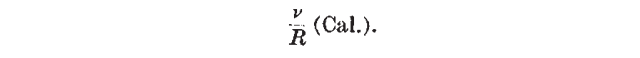 } \\
\hline & \multirow{2}{*}{$\frac{N_{\text {IV }} N_{\text {VI. }}}{\text { Idei. }}$} & \multirow{2}{*}{$\frac{\begin{array}{c}N_{\text {IV }} \\
N_{\text {VI, vir. }}\end{array}}{\begin{array}{c}\text { Bohr } \\
\text { and } \\
\text { Coster. }\end{array}}$} & \multicolumn{2}{|c|}{$N_{\text {IV }} O_{\text {II, }}$ III. } & \multicolumn{2}{|c|}{$N_{\text {IV }} O_{\text {I. }}$} \\
\hline & & & Idei. & $\begin{array}{c}\text { Bohr } \\
\text { and } \\
\text { Coster. }\end{array}$ & Idei. & $\begin{array}{l}\text { Bohr } \\
\text { and } \\
\text { Coster. }\end{array}$ \\
\hline $15 \cdot 6$ & 15.9 & $15 \cdot 5$ & $15 \cdot 0$ & $15 \cdot 4$ & $12 \cdot 6$ & $12 \cdot 7$ \\
\hline $16 \cdot 3$ & $16 \cdot 4$ & $16 \cdot 2$ & 16.0 & $15 \cdot 8$ & $13 \cdot 3$ & $13 \cdot 5$ \\
\hline $18 \cdot 9$ & $18 \cdot 8$ & $19 \cdot 3$ & $20 \cdot 2$ & $15 \cdot 9$ & $16 \cdot 8$ & $17 \cdot 4$ \\
\hline $19 \cdot 5$ & $19 \cdot 6$ & $20 \cdot 0$ & $21 \cdot 7$ & $18 \cdot 1$ & $18 \cdot 2$ & $18 \cdot 6$ \\
\hline
\end{tabular}

LINE WITH LONGER WAVE-LENGTH.

\begin{tabular}{|c|c|c|c|c|c|c|}
\hline$\frac{\nu}{R}$ (Obs.). & \multicolumn{6}{|c|}{$\frac{\nu}{R}$ (Cal.). } \\
\hline \multirow{2}{*}{$\begin{array}{l}\text { Thibaud } \\
\text { and } \\
\text { Soltan. }\end{array}$} & \multicolumn{2}{|c|}{$N V \quad N_{\text {VI, }}$ vir. } & \multicolumn{2}{|c|}{$N_{\mathrm{V}} O_{\mathrm{II}, \mathrm{III}}$} & \multicolumn{2}{|c|}{$N_{\mathrm{V}} O_{\mathrm{I}}$} \\
\hline & Idei. & $\begin{array}{c}\text { Bohr } \\
\text { and } \\
\text { Coster. }\end{array}$ & Idei. & $\begin{array}{c}\text { Bohr } \\
\text { and } \\
\text { Coster. }\end{array}$ & Ideí. & $\begin{array}{l}\text { Bohr } \\
\text { and } \\
\text { Coster. }\end{array}$ \\
\hline $14 \cdot 8$ & $15 \cdot 0$ & $14 \cdot 7$ & $14 \cdot 0$ & $14 \cdot 6$ & $11 \cdot 7$ & $11 \cdot 9$ \\
\hline 15.4 & $15 \cdot 4$ & $15 \cdot 3$ & 14.9 & $14 \cdot 9$ & 12.2 & $12 \cdot 6$ \\
\hline $17 \cdot 8$ & $17 \cdot 8$ & $18 \cdot 0$ & $19 \cdot 0$ & $14 \cdot 6$ & $15 \cdot 6$ & $16 \cdot 1$ \\
\hline 18.4 & $18 \cdot 4$ & $18 \cdot 6$ & $20 \cdot 4$ & $16 \cdot 7$ & $16 \cdot 8$ & $17 \cdot 2$ \\
\hline
\end{tabular}

and Coster for $N_{I V} N_{\mathrm{VI}, \text { vII }}$ and $N_{\mathrm{V}} N_{\mathrm{VI}}$, vII respect. ively, but, due to the inaccuracy of the values for the energy levels, especially for the $O_{\text {I }}$ and $O_{\text {II, III }}$ levels, they were not able to reach any definite conclusions. In a later paper, however, Thibaud (J.O.S.A. and R.S.I., 17, p. $145 ; 1928$ ) ascribes the origin of the two new lines to transitions between the $O$ (probably $O_{\text {II, III }}$ ) level and the $N_{\text {IV }}$ and $N_{\mathrm{V}}$ levels.

I have recently made some careful measurements in the $L$-series, the results of which make possible a more accurate determination of the values of $\nu / R$ for the levels in question. These values, as well as those of Bohr and Coster, are given in the table above with the values of $\nu / R$ for the two newly discovered lines. Judged from these new values, it would seem just as likely that the doublets found by Thibaud and Soltan are due to the transitions $N_{\mathrm{IV}} N_{\mathrm{VI}}$ and $N_{\mathrm{V}} N_{\mathrm{VI}}$ vII. This would then be the first experimental evidence of $\mathrm{X}$-ray transitions within levels of the same principal quantum number. SAKAE IDEI.

Physical Laboratory, Upsala, Mar. 7. 